\title{
Focal nodular hyperplasia of the liver: a link with sickle cell disease?
}

\author{
N D Heaton, J Pain, N C Cowan, J Salisbury, E R Howard
}

\begin{abstract}
Focal nodular hyperplasia is a benign liver tumour that is rare in children. We report the second case of a child with sickle cell disease presenting with symptomatic focal nodular hyperplasia. The possible pathogenesis of focal nodular hyperplasia and the association with sickle cell disease are discussed.
\end{abstract}

Focal nodular hyperplasia of the liver is a rare benign lesion found predominantly in women during their reproductive years. ${ }^{1}$ It consists of a well circumseribed area of hyperplastic liver parenchyma that may contain a stellate fibrous scar. The lesion is usually asymptomatic and is an incidental finding. We describe a patient with sickle cell disease presenting with a symptomatic lesion of focal nodular hyperplasia. This is the second description of such an association ${ }^{2}$ and we discuss whether sickle cell disease is a pathogenetic mechanism for the development of focal nodular hyperplasia.

\section{Case report}

A 6 year old West Indian girl with homozygous SS sickle cell disease presented with abdominal pain, headache, and night sweats. She had been admitted one year previously with a chest infection and sickle crisis. She was taking prophylactic antibiotics. Apart from sickle cell disease there was no other significant medical or family history.

On examination she appeared anaemic but was not jaundiced. A firm non-tender mass was palpable in the epigastrium. The results of biochemical investigations were haemoglobin concentration $72 \mathrm{~g} / \mathrm{l}$, white cell count $8 \cdot 1 \times 10^{9} / \mathrm{l}$, platelet count $213 \times 10^{9} / 1$, albumin $38 \mathrm{~g} / \mathrm{l}$, bilirubin $30 \mu \mathrm{mol} / 1$, and activities of alkaline phosphatase $201 \mathrm{IU} / \mathrm{l}$, aspartate transaminase 111 IU/l, and $\gamma$-glutamyltransferase $146 \mathrm{IU} / \mathrm{l}$. A test for serum $\alpha$ fetoprotein was negative. An ultrasound scan showed a $6 \mathrm{~cm}$ well defined mass in the left lobe of the liver. The lesion had a similar density to normal liver on computed tomography (fig l) and was shown to be avascular on hepatic angiography (fig 2).

At operation, after exchange transfusion, the solid mass was found to be restricted to segments 2 and 3 of the left lobe and was resected. She was discharged home on the ninth postoperative day.

The cut surface of the tumour was smooth with focal areas of haemorrhage, but there was no stellate scar. The microscopic appearance of fibrous bands transecting liver tissue with expanding portal tracts that contained dilated vascular channels and numerous bile ductules was typical of focal nodular hyperplasia (fig 3).

\section{Discussion}

Focal nodular hyperplasia is a rare benign liver tumour with fewer than $20 \%$ of cases presenting in children. ${ }^{3}$ The majority are asymptomatic and usually arise on the surface of the liver beneath the capsule. Their aetiology is unknown, although an association with oral contraceptives has been reported. ${ }^{4}$

The radiological diagnosis depends on identification by ultrasound or computed tomography of a central scar. Angiographic findings of a hypervascular spoke wheel pattern of feeding

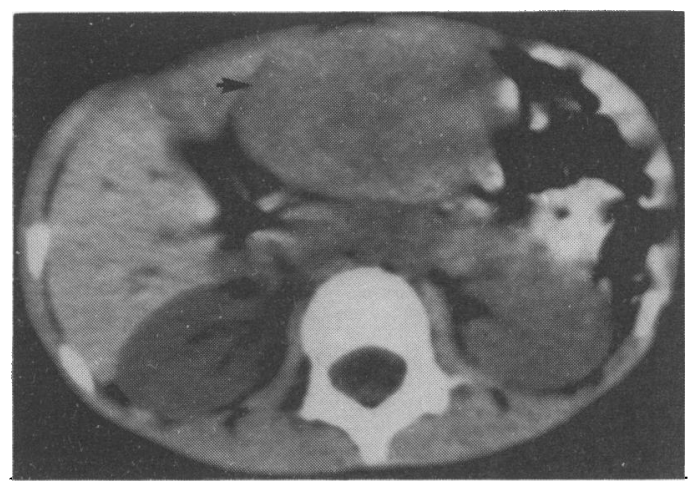

Figurel Computed tomogram without contrast showing the mass in the left lobe of the liver (arrow).

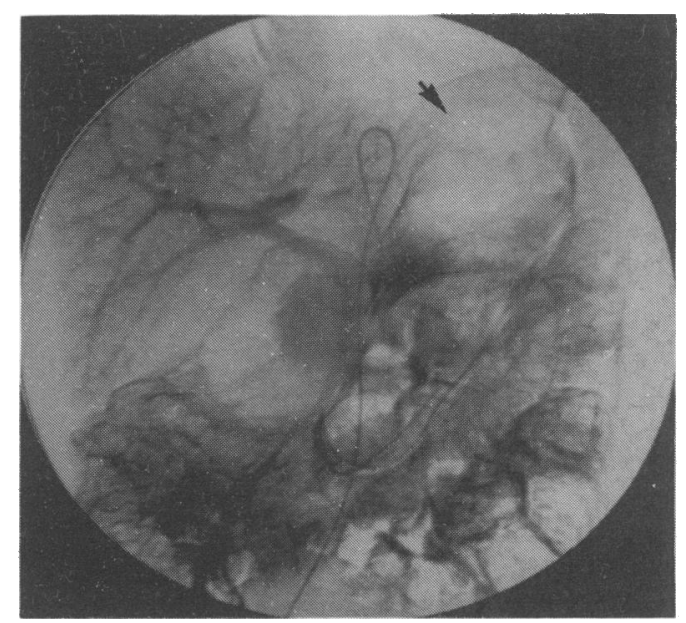

Figure 2 Venous phase of an hepatic digital subtraction angiogram showing an avascular mass in the left lobe of the liver (arrow). 




Figure 3 Section showing regenerative nodules of liver parenchyma (thin arrow) transected by fibrous bands with expanded portal tracts (thick arrow) containing dilated vascular channels and bile ductules (magnification $\times 100)$.

vessels which produce a dense capillary blush are diagnostic but uncommon. ${ }^{5}$

The management of asymptomatic lesions should be to confirm the diagnosis of focal nodular hyperplasia by liver biopsy, excluding benign lesions such as hepatic adenoma, mesenchymal hamartoma, or haemangioma and malignant lesions such as fibrolamellar carcinoma. Ultrasound follow up has been suggested. Symptoms may settle by withdrawal of oral contraceptives, but in other patients symptomatic lesions should be resected or if this is not possible they can be embolised. ${ }^{1}$

The pathogenesis of focal nodular hyperplasia has been considered to be neoplastic, hamartomatous, or a response to ischaemia or other focal injury. It has been suggested that the lesions arise as a hyperplastic response of liver parenchyma to differential blood flow caused by a pre-existing arterial malformation. ${ }^{6}$ Poorly perfused areas undergo atrophy and well perfused areas develop regenerative nodules. Whelan et al suggested that increased blood flow and turbulence caused platelet disruption with thrombosis of smaller arterial vessels that lead to a release of platelet derived growth factor which may stimulate hepatocellular hyperplasia. ${ }^{7}$ Oral contraceptives may affect the hepatic vasculature and influence the development of focal nodular hyperplasia. ${ }^{4}$ Patients taking oral contraceptives tend to have larger, symptomatic lesions sometimes associated with haemangiomata. 18

Occlusive lesions in small arteries and veins may also cause ischaemia followed by atrophy and regenerative nodules. In sickle cell disease blockage of small vessels by deformed red blood cells leads to tissue damage. Sequestration of sickled cells also lead to infarction. The resulting ischaemia and necrosis may provide an explanation for the development of focal nodular hyperplasia. Markowitz et al suggested that the primary abnormality may still be an underlying vascular anomaly and that ischaemia from sickle cell thrombosis acts as a stimulant to the development of focal nodular hyperplasia. ${ }^{2}$

1 Pain JA, Gimson AES, Williams R, Howard ER. Focal nodular hyperplasia of the liver: results of treatment and options in management. Gut 1991;32:524-7.

2 Markowitz RI, Harcke HT, Ritchie WGM, Huff DS. Focal nodular hyperplasia of the liver in a child with sickle cell anaemia. American fournal of Radiology 1980;134:594-7.

3 Stocker JM, Ishak KG. Focal nodular hyperplasia of the liver. A study of 21 pediatric cases. Cancer 1981;48:336-45.

4 Nime F, Pickren JW, Vana J, et al. The histology of live tumours in ural contraceptive users during a tumours in ural contraceptive users during a national 44:1481-7.

5 Welch TJ, Sheedy PJ, Johnson CM, et al. Focal nodular hyperplasia and hepatic adenoma: comparison of angiohyperplasia and hepatic adenoma: comparison of angiography, CT:

6 Wanless IR, Mawdsley C, Adams R. On the pathogenesis of focal nodular hyperplasia of the liver. Hepatology 1985;5: $1194-200$

7 Whelan TJ, Baugh JH, Chandor S. Focal nodular hyperplasia of the liver. Ann Surg 1973;177:150-8.

8 Mathieu D, Zafrani ES, Anglade MC, Dhumeaux D. Association of focal nodular hyperplasia and hepatic hemangioma. Gastroenterology 1989;97:154-7. 